\title{
Low-temperature growth of diamond films using supersonic DC arcjet
}

\author{
A. Romanyuk ${ }^{1}$, H. Güttler ${ }^{1}$, V. Popov ${ }^{2}$ \\ ${ }^{1}$ DaimlerChrysler Research and Technology Center, DaimlerChrysler AG \\ Wilhelm-Runge-Strasse 11, Ulm 89081, Germany \\ ${ }^{2}$ Institute of Semiconductor Physics NAS Ukraine, 45 prospekt Nauki, Kyiv, 03028, Ukraine
}

\begin{abstract}
Diamond film growth on silicon at substrate temperature between 180 to $360^{\circ} \mathrm{C}$ has been studied. The influence of hydrocarbon source on growth conditions and on diamond quality has been also investigated. Several series of experiments were performed to investigate the influence of substrate temperature on the diamond growth rate and the diamond quality. The quality of the deposited diamond films was controlled with Raman spectroscopy. It was shown that using methane as hydrocarbon source the growth rate up to $1.5 \mu \mathrm{m} / \mathrm{h}$ can be achieved. The use of ethane leads to the lower growth rate, but the quality of diamond film, crystallite morphology are better. Decrease of the substrate temperature down to $180^{\circ} \mathrm{C}$ leads to smaller grain size as well as to decreasing of diamond impact in the film.
\end{abstract}

Keywords: diamond film, supersonic arcjet, Raman spectroscopy, electron microscopy.

Paper received 13.06.01; revised manuscript received 24.06.01.; accepted for publication 13.07.01.

\section{Introduction}

Over the last years diamond films have attracted considerable attention with respect to their electrical, optical and thermal properties. Diamond is the hardest of all materials, has a low thermal expansion coefficient, and it is optically transparent from UV to infrared wavelength up to $10 \mu \mathrm{m}$. Furthermore, diamond has by far the highest thermal conductivity at room temperature of a solid state material while being an electrical insulator. These properties make diamond suitable for a wide spectrum of engineering applications. Diamond has found its application in modern microelectronics where the increasing integration level is accompanied by growing thermal load of the devices. To prevent devices from degradation and increase their lifetime new thermal management approaches are required. A temperature reduction of about $10^{\circ} \mathrm{C}$ within the device leads to a doubled mean time between failures. Although $\mathrm{SiO}_{2}$ and $\mathrm{Si}_{3} \mathrm{~N}_{4}$ are standard materials for dielectric isolation in microelectronics their thermal conductivity is rather low. Alternatively, diamond offers good thermal and dielectric properties for thermal management on chips. The realization of diamond deposition onto electronic devices encounters low temperature growth of diamond because with substrate temperature above $400^{\circ} \mathrm{C}$ the performance of the device, will drastically degrade.

Previous research regarding low temperature diamond deposition in microwave [1] and combustion flame systems [2] produced different results. While Muranaka reported that diamond growth follows a simple Arrhenius relation over the entire temperature range between 400 and $800^{\circ} \mathrm{C}$, Snail and Marks suggested that different growth mechanisms may be predominant at lower and higher substrate temperature regimes, respectively. They reported a change in activation energy that takes place around $700^{\circ} \mathrm{C}$, with much higher activation barriers $(22-$ $24 \mathrm{kcal} / \mathrm{mol}$ ) for the higher substrate temperature range of $740-930^{\circ} \mathrm{C}$. The lower temperature $\left(400-700^{\circ} \mathrm{C}\right)$ growth was reported by both groups to be controlled by activation energies under $10 \mathrm{kcal} / \mathrm{mol}$.

Attempts to further understanding surface mechanisms for diamond growth by measuring the sensitivity of the growth rate and diamond quality to large variations in substrate temperature are complicated by the fact that in many diamond processing methods, the adjacent gas phase chemical composition may also be strongly dependent on the substrate temperature [3].

In this paper we report about a series of studies that aimed at taking advantage of the supersonic plasma flow 


\section{A. Romanyuk et al.: Low-temperature growth of diamond films using supersonic ...}

to better develop and refine the understanding of surface chemistry during diamond growth. The sensitivity of diamond growth over a temperature range of 180 to $360^{\circ} \mathrm{C}$ and low temperature limits to diamond film synthesis were investigated. The first experiments were done with hydrocarbon source variation and the following experiments were performed with the substrate temperature as the only one parameter varied.

\section{Experimental}

The $n$-type silicon substrates with (100) orientation and $300 \mu \mathrm{m}$ thick were used. The size of the substrates was $20 \times 20 \mathrm{~mm}$. The substrates were scratched with $0-0.1 \mu \mathrm{m}$ diamond paste and rinsed with isopropanol and ultra pure water. Although nucleation and growth could have been achieved without pre-treatment, the substrates were scratched with diamond paste to enhance nucleation and to minimize variations in growth that may be related to nucleation. The pre-treatment did also enhance reproducibility of the experiments. The supersonic dc arcjet [4] has been used in our experiments. DC arcjet operated with power of $2.7 \mathrm{~kW}$ at constant pressure 0.5 mbar. Methane and ethane were used as hydrocarbon source. The $\mathrm{C} / \mathrm{H}$ ratio was $0.3 \%$ and $\mathrm{O} / \mathrm{C}$ ratio $43-100 \%$. Total flow rate was kept constant at value of $14.61 / \mathrm{min}$. The substrate temperature was measured with cromel-alumel thermocouple from the backside of the substrate. The temperature was controlled by an active cooling system: a) a water-cooled copper and b) a compressed air-cooled stainless steel substrate holder. The distance between the substrates and the arcjet exit plane was $95 \mathrm{~mm}$ and held constants for all series of experiments.

The films were characterized by the Raman peak full width at half maximum (FWHM) as well as the relative impact of the diamond phase with respect to the non-diamond phase. The Raman spectra were recorded using DILOR LabRam in macro mode. For the excitation, Ar laser with the line $488 \mathrm{~nm}$ has been used with power which did not exceed $100 \mathrm{~mW}$. The surface morphology as well as the film thickness were assessed by scanning electron microscopy. SEM micrographs were obtained with PHILIPS XL 40.

Temperature considerations. The substrate temperature is a very important parameter in the chemical vapor synthesis of diamond as it strongly influences crystal size and orientation, film morphology, and diamond quality. Hence, careful monitoring and control of the growth temperature is essential for the production of diamond. In this work, substrate temperature was measured by thermocouple (tc) from the back side of the substrate. The thermocouple technique is foremost invasive but has a number of additional uncertainties. These uncertainties include contact resistance, conduction losses, and a thermal gradient introduced by the distance of the tc-bead to the substrate to be measured. However, if we find a correction for the above errors, the thermocouple measurement is very reliable, since the tc-bead is shielded from the plasma through the substrate itself, and, in addition, the reading is not perturbed by the growing diamond film.

The temperature at a distance of about $500 \mu \mathrm{m}$ behind the diamond growth surface was measured with a spring-supported thermocouple probe $(\mathrm{NiCr}$ positive wire, NiAl negative wire, $0.3 \mathrm{~mm}$ diameter wire, exposed junction, $1.7 \mathrm{~mm}$ diameter ceramic insulator with 2 holes of diameter $0.530 \mathrm{~mm}$ ). In order to minimize the contact resistance between the thermocouple bead and the substrate, the thermocouple bead is pressed against the substrate by means of spring. Typically the error introduced by the contact resistance is $1-2 \%$. The standard limits of error for this-type thermocouple in the temperature range between $-40^{\circ} \mathrm{C}$ and $1000^{\circ} \mathrm{C}$ are given by the manufacturers as $\pm 1.5^{\circ} \mathrm{C}$. Radiation losses of the thermocouple bead are small since it is only exposed to surfaces that are at the temperature it is supposed to measure, except for the ceramic tube. Since ceramic is a thermal insulator, this ceramic tube acts as an insulator for the thermocouple bead as well as the wires. The conduction losses through the thermocouple wires are minimized by using $0.3 \mathrm{~mm}$ diameter wires. In addition to the small diameter wires, the thermal conductivity of the chromel is not very good. That reduces the conduction losses as well. From above considerations, an error of about $10 \%$ can be assumed for the used thermocouple.

Another point, which has to be discussed is temperature gradient between the tc-bead and the surface. For this purpose consider a stationary heat flow in long pivot where temperature gradient $d T / d x$ is created. Then the following relation takes place [5]: $Q=K(d T / d x)$, where $Q$ is a flux of heat energy (energy which is passed through cross-section of the pivot per time moment), $K$ is a coefficient of thermal conductivity. In our case, $Q=100 \mathrm{~W} / \mathrm{cm}^{2}$ and knowing $K$ of silicon $(130 \mathrm{~W} / \mathrm{mK})$ the temperature gradient can be estimated, and it is equal to $\sim 4 \mathrm{~K}$. Above considerations introduce an error of measurement that can be corrected.

\section{Results and discussion}

Fig. 1 shows the SEM micrographs of diamond film deposited with $\mathrm{C}_{2} \mathrm{H}_{4}$ as a hydrocarbon source at substrate temperature $360^{\circ} \mathrm{C}$ for run duration of 240 minutes with $\mathrm{C} / \mathrm{H}$ ratio $0.3 \%$ and $\mathrm{O} / \mathrm{C} 43 \%$. It leads to growth of uniform film and a morphology dominated by (111) facets on uniform and flat films with small average crystal size of about $1.2 \mu \mathrm{m}$, which is characteristic of the high flux diamond deposition technique. The growth rate of $0.7 \mu \mathrm{m}$ per hour is observed. At the same time use of $\mathrm{CH}_{4}$ as hydrocarbon source with $\mathrm{O} / \mathrm{C}$ ratio $67 \%$ but keeping $\mathrm{C} / \mathrm{H}$ ratio constant yielded an uniform film of $1.5 \mu \mathrm{m}$ thick after run duration of $60 \mathrm{~min}$. It can be easily seen that the crystal size dramatically decreases (Fig 2). Fig. 3 depicts the Raman spectra of the diamond films discussed above. The best Raman quality is found for the film grown using $\mathrm{C}_{2} \mathrm{H}_{4}$. This film has the smallest full width at half maximum (FWHM) of the zone center $1332 \mathrm{~cm}^{-1}$ peak, the high signal intensity, and the least relative signal contribution from the non-diamond phases. The film grown with 
A. Romanyuk et al.: Low-temperature growth of diamond films using supersonic ...
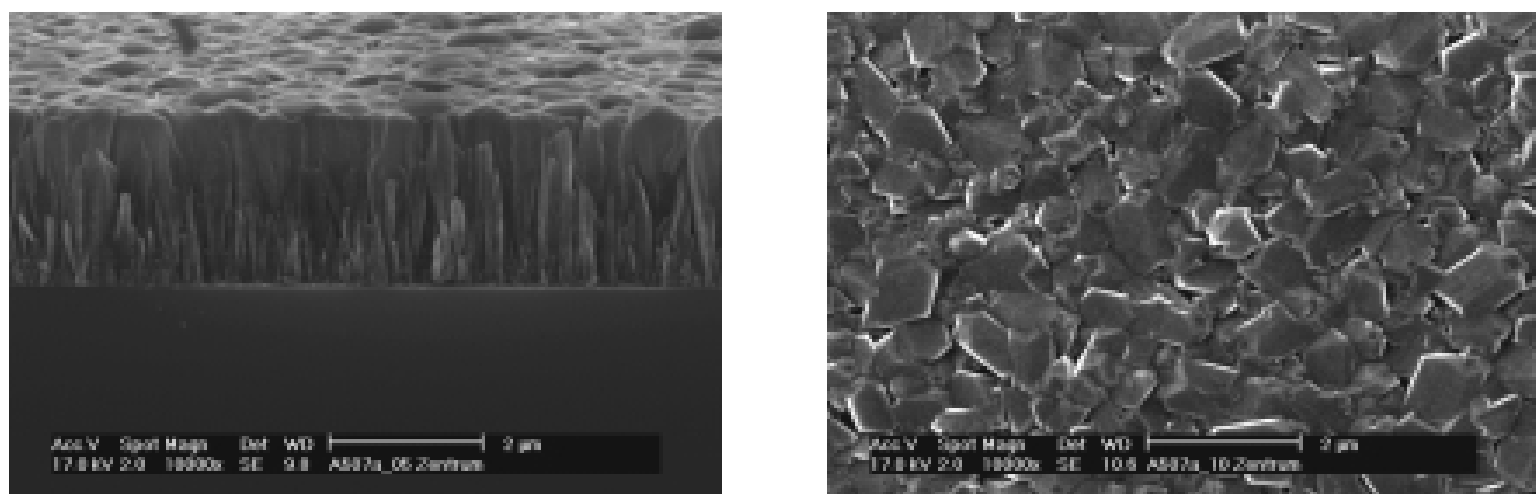

Fig. 1. SEM micrographs of diamond film grown with $\mathrm{C}_{2} \mathrm{H}_{4}$ as hydrocarbon source after run duration of $240 \mathrm{~min}$. $\mathrm{C} / \mathrm{H}$ ratio is $0.3 \%$ and $\mathrm{O} / \mathrm{C}$ is $43 \%$. Substrate temperature $T_{s}=360^{\circ} \mathrm{C}$.
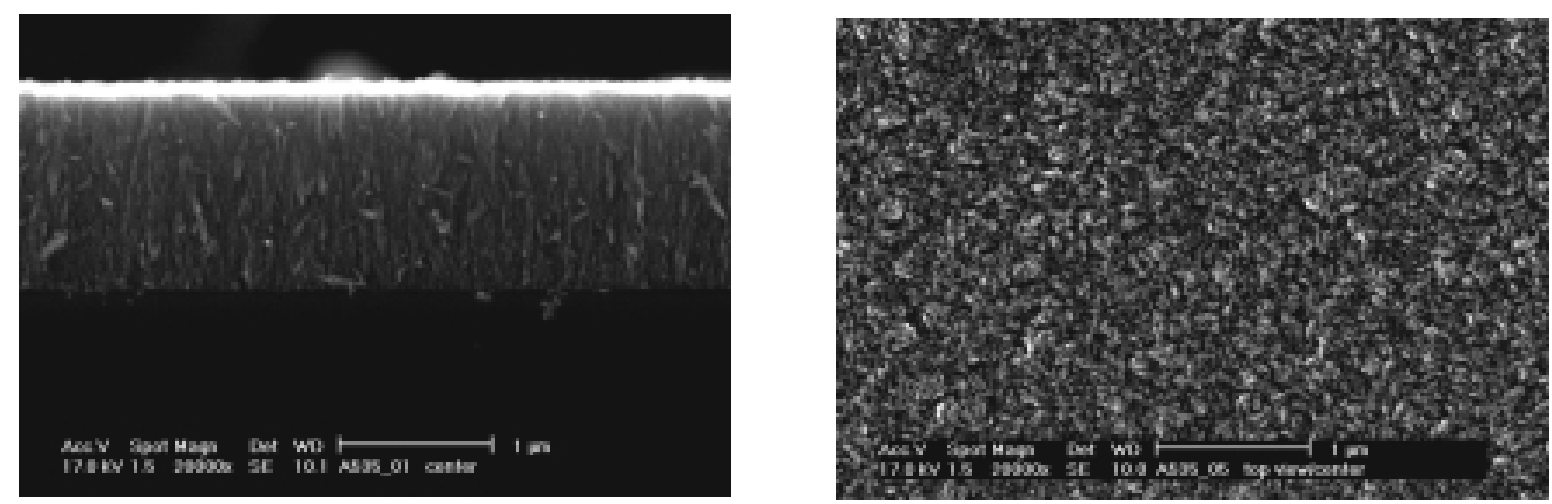

Fig. 2. SEM micrographs of diamond film grown with $\mathrm{CH}_{4}$ as hydrocarbon source after run duration of $60 \mathrm{~min}$. $\mathrm{C} / \mathrm{H}$ ratio is $0.3 \%$ and $\mathrm{O} / \mathrm{C}$ is $67 \%$. Substrate temperature $T_{s}=360^{\circ} \mathrm{C}$.
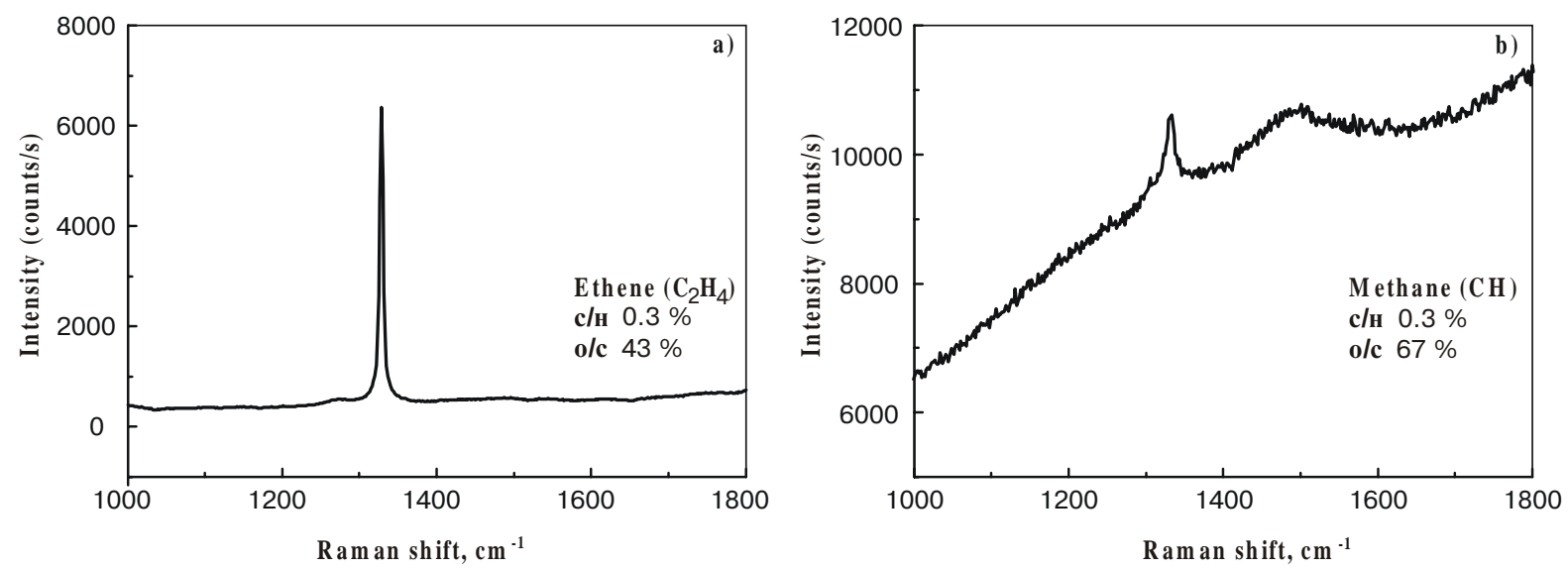

Fig. 3. Raman spectra of diamond films: a) with $\mathrm{C}_{2} \mathrm{H}_{4}$ as hydrocarbon source, $\mathrm{C} / \mathrm{H} 0.3 \%, \mathrm{O} / \mathrm{C} 43 \%$ and b) with $\mathrm{CH}_{4}$ as hydrocarbon source, $\mathrm{C} / \mathrm{H} 0.3 \%$, O/C $67 \%$. 

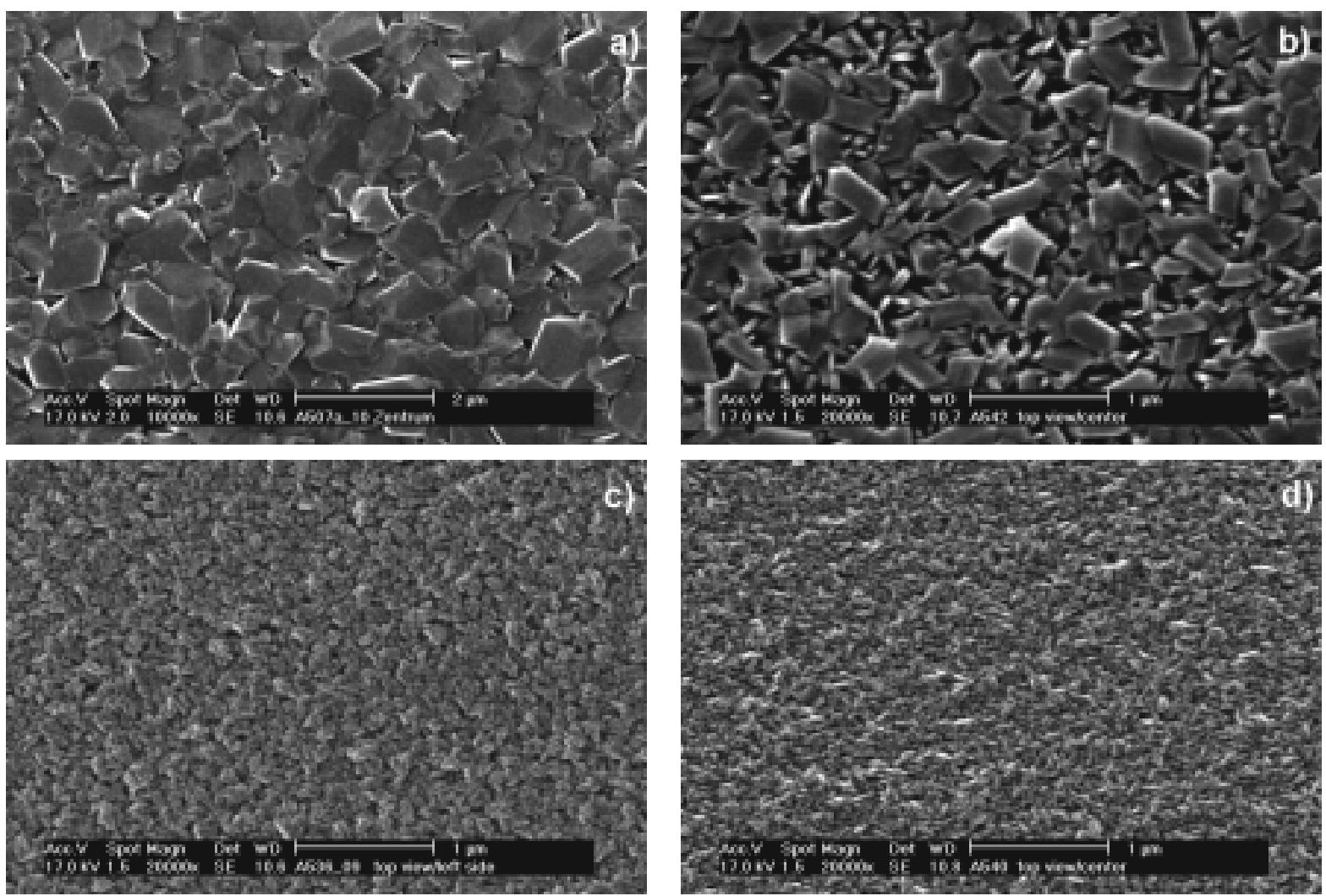

Fig. 4. SEM micrographs of diamond film grown with $\mathrm{C}_{2} \mathrm{H}_{4}$ as hydrocarbon source after run duration of $60 \mathrm{~min}$. $\mathrm{C} / \mathrm{H}$ ratio is $0.3 \%$ and $\mathrm{O} / \mathrm{C}$ is $43 \%$. Substrate temperature: a) $T_{s}=360^{\circ} \mathrm{C}$, b) $T_{s}=270^{\circ} \mathrm{C}$, c) $T_{s}=220^{\circ} \mathrm{C}$, d) $T_{s}=180^{\circ} \mathrm{C}$.

$\mathrm{CH}_{4}$ is characterized by weak and relatively broad peaks at $1332 \mathrm{~cm}^{-1}$ and at $1470 \mathrm{~cm}^{-1}$ that shows high impact of non-diamond phase.

Average film thickness was determined by SEM analysis of film cross-sections. Since the nucleation time is not exactly known for these particular conditions, it is not possible to accurately specify growth rates. However, it is assumed that pre-treating all substrates in the identical manner minimizes the difference within one particular series. Then the «average» growth rates can be estimated from the film thickness divided by the run duration. It is seen that injected ethane also serves to grow diamond of good quality, at twice the rates to those measured for similar injected methane flow rates.

Fig. 4 shows SEM images of diamond deposits grown at substrate temperature between 360 and $180^{\circ} \mathrm{C}$ for run duration of 120 minutes.

Apparent from these micrographs is the transition from preliminary (111) faced films at $360^{\circ} \mathrm{C}$ to disordered films at $180^{\circ} \mathrm{C}$. It is also apparent that the crystal size decreases for lower substrate temperature. At the lowest substrate temperatures the crystallinity degrades substantially. Fig. 5 shows macro Raman spectra corresponding to the SEM's in Fig. 4. From the spectra, it is obvious that the best quality is obtained for temperature $360^{\circ} \mathrm{C}$. This coincides with conditions where (111) surfaces are the most prevalent. At low temperatures, increasingly persistent features at $1470 \mathrm{~cm}^{-1}$ are observed while FWHM of dia- mond peak degrades only slightly. The growth rate for films deposited at substrate temperatures 270 and $220^{\circ} \mathrm{C}$ is $0.6 \mu \mathrm{m} / \mathrm{h}$ while for the substrate temperature of $180^{\circ} \mathrm{C}$ it decreases only slightly and the value of $0.5 \mu \mathrm{m} / \mathrm{h}$ is observed.

Such a high growth rate for low temperature deposition can be explained by copious amount of atomic hydrogen provided by the arcjet system. Atomic hydrogen plays important role in growth kinetics by preventing surface reconstruction of the growing diamond film into graphitic $s p^{2}$ through satisfying the dangling bonds of the surface carbon. This keeps surface carbon bonds in stable, $s p^{3}$-hybridized configuration. The second major impact hydrogen is believed to have is the production of active growth sites, or the so-called radical surface sites, through abstraction of surface hydrogen [6]. Other possible involvement of atomic hydrogen is speculated to be $\mathrm{H}$-abstraction from surface hydrocarbons, assisting the incorporation of these adsorbed species into the diamond lattice. Frenklach [7] added that the key role of hydrogen in the diamond deposition process is to suppress the formation of aromatic species by $\mathrm{H}_{2}$ in the gas phase and thereby to prevent the formation and growth of non-diamond, graphitic phases on the deposition surface. Also the addition of oxygen substantially reduces the growth rate but adding of oxygen is necessary to suppress the degradation in crystallinity that is likely occurs at low temperatures. 
A. Romanyuk et al.: Low-temperature growth of diamond films using supersonic ...
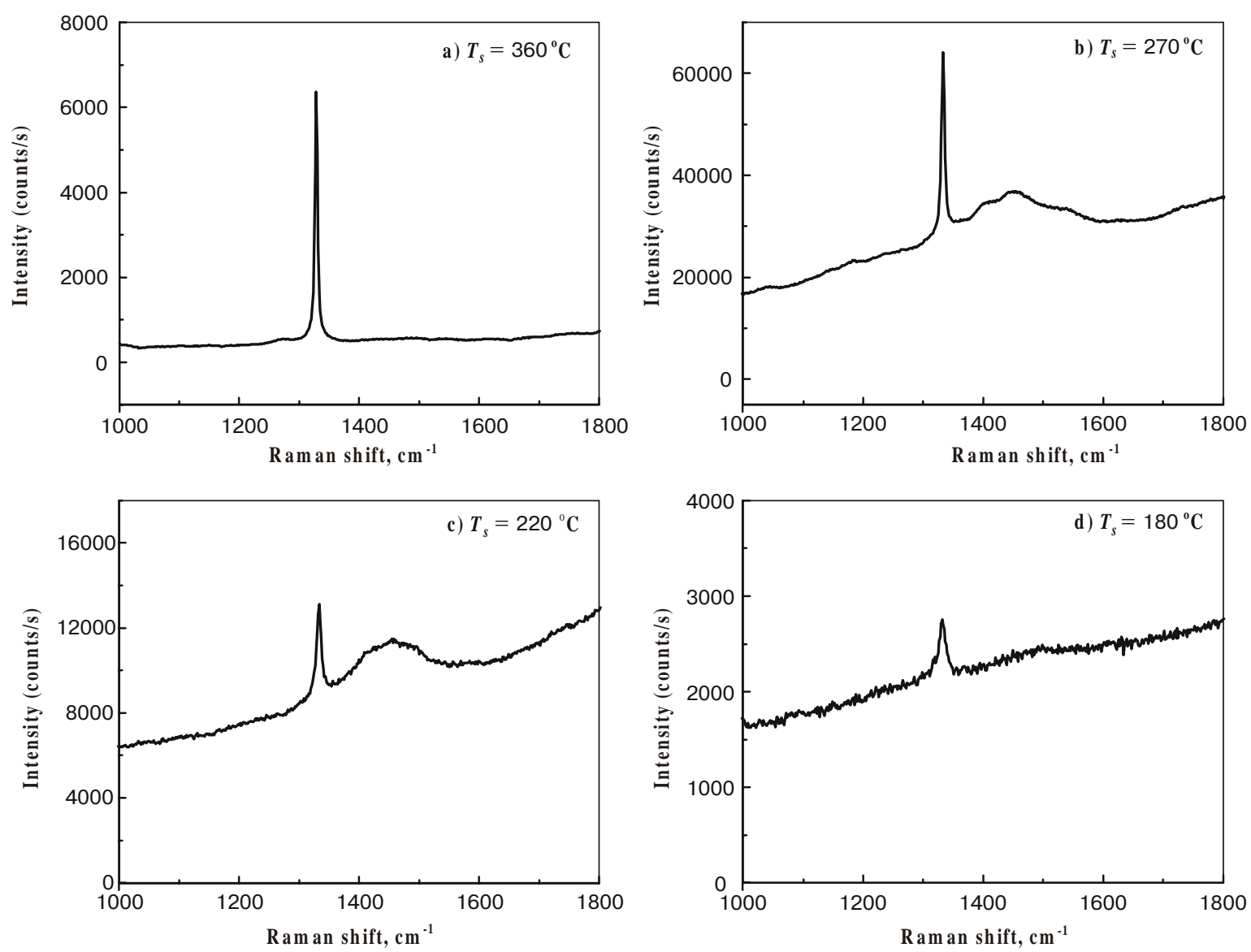

Fig. 5. Raman spectra of diamond films grown with $\mathrm{C}_{2} \mathrm{H}_{4}$ as hydrocarbon source after run duration of $60 \mathrm{~min}$. $\mathrm{C} / \mathrm{H}$ ratio is $0.3 \%, \mathrm{O} /$ C is $43 \%$. Substrate temperature: a) $T_{s}=360^{\circ} \mathrm{C}$, b) $\left.T_{s}=270^{\circ} \mathrm{C}, \mathrm{c}\right) T_{s}=220^{\circ} \mathrm{C}$, d) $T_{s}=180^{\circ} \mathrm{C}$.

\section{Conclusions}

In this work a new approach to diamond film synthesis is presented. The prime novelty of the process is based on a supersonic low-density hydrogen plasma flow generated by means of direct-current arcjet. The post-nozzle injection of hydrocarbon source gases creates diamond growth conditions at a downstream substrate. This diamond growth method combines a number of significant advantages such as high diamond growth rates, due to the high species fluxes, and excellent diamond quality. The observed growth rate $(0.5-1.5 \mu \mathrm{m} / \mathrm{h})$ is much greater to that observed in hot filament and microwave plasma synthesis of diamond films. With this facility, a high quality diamond film synthesis from either methane or ethane source gases was demonstrated. We have shown that use of methane as a hydrocarbon source gas leads to higher growth rate compare to the ethane hydrocarbon source gas. However, films deposited with methane loss the crystallinity as well as diamond impact in the film is less than for the films deposited with ethane. Low temperature deposition of diamond films with ethane hydrocarbon source gas was also demonstrated. It is shown that temperature decreasing leads to decreasing crystallite sizes and increasing graphitic impact in the film. For the films deposited at temperature $180^{\circ} \mathrm{C}$ cristallinity degrades substantially.
Much of the above can be attributed to copious amount of atomic hydrogen that are generated in the hot arc discharge. The large atomic hydrogen densities are major contributors to the success of this process, since hydrogen seems to be the single most important growth species.

\section{References}

1. Y. Muranaka, H. Yamashita and H. Miyadera, Characterization of diamond films synthesized in the microwave plasmas of $\mathrm{CO} / \mathrm{H}_{2}$ and $\mathrm{CO} / \mathrm{O}_{2} / \mathrm{H}_{2}$ systems at low temperatures (403 1023 K) // J. Appl. Phys. 69 (12), pp.8145-8148 (1991).

2. K.A. Snail and C.M. Marks, In situ diamond growth rate measurement using emission interferometry // Appl. Phys. Lett. 60 (25), p.p. 3135-3137 (1992).

3. E.J. Corat and D.G. Goodwin, Temperature dependence of species concentration near the substrate during diamond chemical vapor deposition // J. Appl. Phys. 74 (3), pp. 20212026 (1993).

4. M.H. Loh, A study of diamond synthesis in an expanding arcjet plasma flow. High Temperature Gasodynamics Lab., Mechanical Eng. Dept, Stanford University. Report No TSD106 (1997).

5. C. Kittel, Introduction to solid state physics, John Wiley and Sons Inc, N.Y. (1978).

6. M. Frenklach and K.E. Spear, Growth mechanism of vapor deposited diamond // J. Mat. Res. 3 (1), pp. 133-137 (1988).

7. M. Frenklach, The role of hydrogen in vapor deposition of diamond // J. Appl. Phys. 65 (12), pp. 5142-5147 (1989). 